\title{
Nuestros colaboradores
}

Números

$6 \quad$ Luis Aguilar

7 Antonio Alatorre

2, 3 y 4 Luis Astey.

$5 \quad$ Laura Benitez

1 José Ramón Benito

3 Mauricio Beuchot
Profesor de Ciencia política y de Filosofia (UNAM)

Profesor-investigador del

Colegio de México (Centro de

Estudios Lingüísticos y

Literarios). Miembro del Colegio

Nacional.

Profesor de Literatura clásica

(ITAM) y medieval (UNAM y

Colegio de México).

Profesora de Historia de la filosofia (UNAM). Es autora de La idea de historia en Carlos de Sigüenza y Góngora.

Profesor de Etica social y de Historia de las ideas (ITAM).

Profesor de Filosofia del lenguaje y de Filosofía de la Edad Media (UNAM). $\mathrm{Ha}$ publicado El problema de los universales. 
Números

2 y 3 Eduardo Blanquel

Prolesor de Historia de México (UNAM). Fue coordinador general del semanario Tiempo de Méxica, editado por la SEP. Ha publicado diversos artículos en revistas especializadas.

4 Victoria Camps

Profesora de Etica (Universidad Autónoma de Barcelona, España). Su libro más reciente: La imaginación ética.

3 Antonio Carrillo Flores

Ocupó diversos cargos públicos de alta responsabilidad en el área financicra y en el servicio extcrior. Fue rector del ITAM y micmbro de su Junta de Gobienro.

4 Cornelius Castoriadis.

Su último libro, Domaines de l'homme, Les carrefours du labyrinthe 11 (1986), amplia y profundiza la rellexión iniciada en Les carrefours du labyrinthe.

5 Manuel Ceballos

Prolesor de Historia de México (Colegio de México). Es autor de una antología de lecturas: Teoría de la historia, y colaboró en el libro La lectura y los lectores en México.

2 E.M. Cioran

Escritor de lengua francesa y nacido en Rumania, se declara apátrida. Breviario de podredumbre, Del inconveniente de haber nacido cuentan entre sus libros.

1, 4 y 6 Paulette Dieterlen

Profésora de Filosofia de la economía y de Filosofia política (ITAM y UNAM). 
Números

2 Javier Elguea

5 y 7 Elsa Cecilia Frost

2 José Gaos

7. Federico García Lorca

3 Javier Gavito

$6 \quad$ Michel Gillet
Profesor de Filosofía de la ciencia y de Sociología del desarrollo (Colegio de México).

Profesoma de Filosofía y de Historia de las ideas (UNAM). Es autora de Las categorias de la cultura mexicana. Ha publicado diversos articulos en revistas especializadas.

Transterrado en México en 1938; desarrolló una labor ejemplar que amplió y profundizó la que había comenzado en su España natal. Su obra docente, su obra ensayística y de traductor estuvo sicmpre en la vanguardia de las corrientes filosóficas de nuestro tiempo y de nuestra circunstancia.

Miembro destacado de una brillantísima generación de poetas españoles, estuvo imaginativamente atento a las raices populares del canto y la poesía. Su obra es ampliamente conocida. En este número (7) publicamos poemas suyos hasta ahora inéditos en México.

Profesor de Finanzas y de Teoría de la autogestión (ITAM).

Especialista en novela popular francesa del siglo XIX.

Interesado en la personalidad del célebre inspector Vidoc. 
Números

$5 \quad$ Edgar González

5 Juliana González

1 Héctor González Uribe

6 Gilbert Hardy

7. Charles Harsthorne

3. Carlos de la Isla

3
Profesor de Historia de las ideas (ITAM).

Profesora de Ontología y de Filosofia griega (UNAM). Su libro más reciente: $E l$ malestar en la moral.

Profesor de Filosofia política (UNAM y UIA).

Decano de filosofía de la Universidad de Dallas. Es autor, entre otros libros de La vocation de la liberté chez Louis Lavelle.

Profesor de Metafísica, Filosofia de la religión y Estética de las Universidades de Harvard, de Chicago y, desde 1962, de Texas. Es autor, entre otros libros, de $M$ an's. Vision of God and the Logic of Theism

Profesor de Historia de las ideas y de Filosofía de la educación (ITAM).

Profesor de Historia de la filosofía moderna en Varsovia hasta su destitución, en 1968, y después, sucesivamente en Montreal, Berkeley y Oxford, donde reside actualmente. Es autor, entre otros libros, de Vigencia y caducidad de las tradiciones cristianas y Husserl y la búsqueda de la certeza. 
Números

1. Milan Kundera

1 Rafacl Landerreche

3. Claude Lefort

2. León Felipe

6

Alfonso Martínez

$7 \quad$ Lorenzo Meyer
Su última novela se traclujo al español con el título de $L a$ insoportable levedad del ser.

Actualmente es profesor de literatura en l'Ecole Pratique dès Hautes Etudes de París.

Responsable de la Biblioteca Manuel Gómez Morín del ITAM donde ha sido profesor de Historia de México.

Director de Estudios en la Ecole des Hautes Etudes en Sciences Sociales de París. Su libro más importante Le travail de l'oeuvre, Machiavel permanece inédito en español.

Por sus temas y la fuerza de su voz, es conocido como el poeta del exilio español en México. Sus libros más conocidos son Ganarás la luz y ;Oh, este viejo y roto violin!

Profesor de Historia del arte (Colegio de México). Publicó recientemente El gran teatro de un pequeño mundo. El Carmen de San Luis Potosi, 1732-1859.

Profesor de Ciencia política (Colegio de México). Ha publicado, entre otros libros, México y los Estados Unidos en el conflicto petrolero y Los grupos de presión extranjeros en el México revolucionario. 
Números

1 y 5 Julián Meza

5 Pablo Noriega

2, 4 y 7 Abraham Nosnik

$5 \quad$ Boris Pasternak

4 y 7 Rodelfo Pastor

2 Octavio Paz

4 Carlos Pereda

3 Sergio Pérez Cortés

4 Rainer María Rilke
Profesor de Filosofía política y de Literatura moderna (ITAM y UNAM).

Profesor de Informática (Universidad Anáhuac).

Profesor de Filosofía de la ciencia (ITAM).

Más allá de las fechas Estudios (No. 4,5 y 6) restableció arbitrariamente la correspondencia entre los poetas de Cartas del verano de 1926: B. Pasternak, R. M. Rilke y $M$. Tsvietáiera, gracias a Uwe Frish, Sclma Ancira y Gerardo Torres.

Profesor de Historia indigena y campesina (Colegio de México). Publicará proximainente su tesis de doctorado: Campesinos y reforma: la mixteca, 1748-1856.

Siempre fiel a Libertad bajo palabra, "La palabra se levanta de la página escrita"' reitera nuestro mayor poeta y ensayista.

Profesor de Filosofia contemporánea (UAM y UNAM).

Profesor de Epistemologia de las ciencias sociales (UAM). Es autor del libro La primera crítica de la economía política.

Ver B. Pasternak 
Números

7

6

Maryze Rozat

2

Jaime Ruiz de Santiago

5

Lizbeth Sagols

$5 \quad$ Victor Serge

1, 4 y 6 Jorge Serrano

2

Julia Sierra
Miembro del Sindicato

Solidaridad.

Profesora de Demografia en la Universidad de París.

Profesor de Etica y de Filosofia del derecho. Actualmente es Alto Comisionado de las Naciones Unidas para Los Refugiados.

Profesora de Filosofía (UNAM).

En 1928, al borde de la muerte, en un hospital de Leningrado Serge decidió escribir sobre cosas durables. El impulso de entonces se mantuvo; en 1944 en Acapulco, escribió: "Sobre las playas las olas son altas y violentas. Al Pie de la Cuesta se las ve venir rodando pesadamente, acarreando agua admirablemente verde $y$ explosiones de espuma. Me da la impresión de una fuerza absoluta, elemental y por lo tanto, inintelegible" (Carnets, p. 128).

Profesor de Filosofía de la ciencia y de Epistemología (ITAM). Su libro más reciente: La reducción en las ciencias.

Profesora de Historia de México. y de Antropologia social y económica (ITAM). 
Números

2 Reynaldo Sordo

2. Eduardo Subirats

3 Gerardo Torres

$3 \quad$ Elias Trabulse

6 Marina Tsvietáieva

2 José Vasconcelos

I y 2 Rodolfo Vázquez

1 y 5 Ramón Xirau
Protesor de Historia de México (ITAM).

Es autor, entre otros libros, de $E l$ alma y la muerte y de De las vanguardias al post-modernismo.

Jefe de redacción de Estudios (Nos. 2 a 6). Ha colaborado en diversas publicaciones literarias. Sc dedica a la poesía.

Prolesor de Historia de la ciencia en México (Colegio de México). Es autor de una obra fundamental: Itistoria de la ciencia en Mévico.

Ver B. Pasternak.

Uno de los forjadore's del México contemporáneo. Político, escritor, filossofo fue un hombre apasionado que no quiso guardar silencio.

Profesor de Historia de las ideas, de Filosolia del derecho y de Filosolía de la religión (ITAM).

Profesor de filosofia de la religión (UNAM). Miembro del Colegio Nacional. Su libro más reciente: Cuatro filósofos y lo sagrado: Teilhard de Chardin, Wittgestein, Heidegger y Simone Weil. 


\section{Números}

$2 \quad$ Leopoldo Zea

1 Ramón Zorrilla
Director de CC y DEL. Autor, entre otros libros, de $E l$ positivismo en México.

Profesor de Filosolía y de Historia de las ideas (ITAM). 